\title{
EXPERIÊNCIAS AGROECOLÓGICAS NO IFCE CAMPUS CRATO: REFLEXÕES SOBRE EDUCAÇÃO E CONVIVÊNCIA COM O MEIO AMBIENTE NO CARIRI CEARENSE
}

\author{
Alaíde Régia Sena Nery de Oliveira ${ }^{1}$ \\ Joseilde Amaro dos Santos ${ }^{2}$ \\ Djane AlvesVictor ${ }^{3}$ \\ Damiana Vicente da Silva ${ }^{4}$ \\ Ivania Maria de Sousa Carvalho Rafael ${ }^{5}$
}

\section{RESUMO}

Este trabalho propõe algumas reflexões acerca das experiências em agroecologia de estudantes egressas do IFCE, Campus Crato, que vivenciam no meio rural, e fora dele, momentos significativos de aprendizado. Relata experiências positivas com relação a vivência da família de uma produtora rural e também ex-discente do campus que começou a ser observada pela instituição de ensino e que tem suas experiências aliadas aos estudos e vivências educativas. Este exercício é encarado como uma interação entre teoria e prática que vem crescendo mediante as situações mencionadas no texto. Nessa conjuntura, o trabalho também enfatiza a importância de considerar e valorizar o conhecimento empírico, associando-o ao conhecimento científico, como uma das bases para a construção da educação contextualizada ao meio ambiente.

Palavras - Chave: Agroecologia. Experiência. Produção.

\begin{abstract}
This work proposes some reflections about the agroecology experiences of students from the IFCE, Campus Crato, who experience in rural areas, and outside, significant learning moments. It reports positive experiences regarding the experience of the family of a rural producer and also a former student of the campus who began to be observed by the

\footnotetext{
${ }^{1}$ Mestranda em Educação Agrícola pela Universidade Federal Rural do Rio de Janeiro- UFRRJ; Bacharel em Comunicação Social/Jornalismo em Mutimeios pela UNEB/DCHIII; Graduada em Pedagogia pela Universidade de Pernambuco (UPE); Pedagoga do IFCE Campus Crato;

${ }^{2}$ Mestranda em Educação Agrícola pela Universidade Federal Rural do Rio de Janeiro- UFRRJ; Graduada em Pedagogia pela Universidade Regional do Cariri (URCA); Técnica em Assuntos Educacionais do IFCE Campus Crato;

${ }^{3}$ Especialista em Gestão Escolar e Coordenação Pedagógica pela Faculdade Kurios; Graduada em Pedagogia pela Universidade Estadual do Ceará (UECE); Pedagoga do IFCE Campus Crato;

${ }^{4}$ Graduada em Pedagogia pela Faculdade kurios; Técnica em Agropecuária pelo IFCE Campus Crato; Produtora Rural da Comunidade Sítio Lírio;

${ }^{5}$ Mestra em Educação pelo Mestrado Acadêmico Intercampi em Educação e Ensino - MAIE da UECE (FAFIDAM/FECLESC); Graduada em Pedagogia pela Universidade Regional do Cariri (URCA); Técnica em Assuntos Educacionais do IFCE - Campus Juazeiro do Norte.
} 
educational institution and who has her experiences allied to studies and educational experiences. This exercise is seen as an interaction between theory and practice that is growing through the situations mentioned in the text. In this context, the work also emphasizes the importance of considering and valuing empirical knowledge, associating it with scientific knowledge, as one of the bases for the construction of education contextualized to the environment.

Key-words : Agroecology . Experience. Production.

\section{RESUMEN}

Este trabajo propone algunas reflexiones acerca de las experiencias en agroecología de estudiantes egresados del IFCE, Campus Crato, que vivencian en el medio rural, y fuera de él, momentos significativos de aprendizaje. Relata experiencias positivas con relación a la vivencia de la familia de una productora rural y también ex discente del campus que comenzó a ser observada por la institución de enseñanza y que tiene sus experiencias aliadas a los estudios y vivencias educativas. Este ejercicio se considera como una interacción entre teoría y práctica que viene creciendo a través de las situaciones mencionadas en el texto. En esta coyuntura, el trabajo también enfatiza la importancia de considerar y valorar el conocimiento empírico, asociándolo al conocimiento científico, como una de las bases para la construcción de la educación contextualizada al medio ambiente.

Palabras clave: Agroecología. Experiencia. Producción.

\section{1- INTRODUÇÃ̃o}

Este artigo aborda experiências agroecológicas de algumas estudantes egressas do Instituto Federal de Educação, Ciência e Tecnologia do Ceará - IFCE Campus Crato - e tem como objetivo propor reflexões sobre a importância da relação entre educação e a convivência e com o meio ambiente, em especial com o ambiente semiárido.

Com 776 estudantes, distribuídos entre o Ensino Técnico em Agropecuária e em Informática Integrados ao Ensino Médio; Subsequente em Agropecuária e Superior (Bacharelado em Zootecnia e Bacharelado em Sistemas de Informação); o IFCE Campus Crato é um espaço plural.

Desde os seus primeiros momentos de existência enquanto ambiente educativo, a antiga Escola Agrícola, hoje Campus Crato recebe pessoas de lugares, crenças e hábitos diversos. São múltiplas experiências e saberes que enriquecem a vivência diária no campus. Entre as experiências atuais tem destaque, no âmbito da agroecologia e da agricultura familiar, a experiência da agricultora que concluiu recentemente o curso Técnico em Agropecuária no Campus Crato; Damiana Vicente da Silva (41 anos) e de suas filhas Larissa da Silva dos Santos (21) e Maria Laís da Silva Santos (19). Todas elas cursaram o Ensino Técnico Subsequente em Agropecuária e já o concluíram. Maria Laís, por sua vez continua no 
Campus cursando a Graduação em Zootecnia. Damiana decidiu voltar a estudar com a pretensão de aperfeiçoar os seus conhecimentos, mas superou as suas intenções iniciais, já que hoje instiga a curiosidade da instituição onde estudou, contribuindo, assim, com as inovações para a comunidade acadêmica.

Residentes na comunidade rural Sítio Lírio, localizada no Município de Santana do Cariri, não faltam disposição e ideias para a família implementar ações que envolvam o IFCE e a comunidade em experiências que buscam conservar o meio ambiente e sejam adaptadas ao clima semiárido, também característico da região Sul do Ceará e do Cariri Cearense ${ }^{6}$.

A família começou o trabalho com agroecologia há16 anos. Hoje na propriedade da residência (área de seis hectares) são cultivados legumes, hortaliças diversas, frutas nativas, doces caseiros, além da produção de mel de abelha e de animais de pequeno porte, como aves, suínos, caprinos e ovinos, bem como uma área preservada de vegetação nativa. Toda a produção, que é livre de veneno, é irrigada com a ajuda da cisterna calçadão ${ }^{7}$ de 52 mil litros. $\mathrm{O}$ excedente é vendido na feira agroecológica do município do Crato-CE que acontece todas as sextas-feiras e em outros espaços comerciais da região. Damiana e sua família (composta por cinco membros) conta com o apoio da Associação Cristã de Base (ACB), uma organização não governamental que atua no Cariri Cearense há mais de 30 anos e trabalha com políticas públicas voltadas para a articulação das comunidades rurais, prestando assessoria a agricultores e agricultoras familiares no intuito de potencializar a produção e o convívio harmônico com o meio ambiente, respeitando a natureza e os saberes populares.

Damiana e suas filhas utilizaram os conhecimentos produzidos em sala de aula para as práticas no meio rural, mais especificamente no quintal produtivo ${ }^{8}$ da família, adaptando esses conhecimentos ao contexto local e os tornando significativos, de modo a realizar a contextualização do ensino. A Educação contextualizada, dessa forma, é também uma possibilidade de superação, empoderamento e de inclusão da mulher no mundo educativo e do trabalho. Assim, “a proposta de Educação Contextualizada no Semiárido não pode limitar-se somente aos aspectos didáticos-pedagógicos, precisa assumir um caráter político-pedagógico de transformação.”(LIMA, 2010, p 160-161).

E a partir da transformação de atitudes, a agricultora supracitada revela hoje que é

\footnotetext{
${ }^{6}$ Microrregião do Estado do Ceará formada pelos munícipios de Barbalha, Crato, Jardim, Juazeiro do Norte, Missão Velha, Nova Olinda, Porteiras e Santana do Cariri. Em sua vegetação possui cerradão, mata atlântica, cerrado e caatinga.

${ }^{7}$ Tecnologia que consiste num espaço para captação de água de chuva. Um reservatório que tem como objetivo armazenar a água para a produção de alimentos, plantas e criação de pequenos animais, melhorando os quintais produtivos. A sua capacidade de armazenamento de água é de 52 mil litros de água.

${ }^{8}$ Unidade de produção familiar situada ao redor da residência. Nesse espaço podem ser cultivadas plantas frutíferas, medicinais, condimentais, hortaliças e a criação de pequenos animais e outros cultivos.
} 
preciso reconhecer que o contexto local é importante para a construção do conhecimento sem perder de vista a vivência harmônica com o meio social e ambiental. "Não foi tão fácil adaptar o que eu aprendi na sala de aula com o cultivo e a criação, mas depois que conseguimos colocar em prática os conhecimentos da escola nesse quintal produtivo, melhoramos muito a produção, os lucros e a nossa qualidade de vida. Hoje eu, meu esposo e meus filhos fazemos a nossa própria renda a partir dessa adaptação", revela Damiana. Ela também concorda com a necessidade de considerar que a escola pode contribuir de modo expressivo para a articulação do conhecimento científico com o saber popular e assim provocar a inclusão. Com isto, Damiana faz uma espécie de chamado dos conteúdos escolares para a vivência no quintal e assim tematiza e articula os assuntos que considera mais pertinentes.

Persistentes e atuantes, Damiana e suas filhas tem a convicção de que podem sempre melhorar os trabalhos desenvolvidos a partir da conexão entre a teoria e a prática. E foi a pretensão de intensificar essa conexão uma das razões que as motivou a cursarem o curso Técnico em Agropecuária no IFCE - Campus Crato, na modalidade Subsequente. Percebe-se com isto o quanto é importante a inserção da comunidade local no ambiente escolar, principalmente quando há uma prática pedagógica emancipatória em que os alunos apropriam-se do conhecimento de forma significativa, fruto do resultado do processo de ligação entre realidade do aluno e conhecimento científico, e experiência de vida. Para Saviani:

O conhecimento, portanto, que é processo, tem de ser alcançado na relação dialógica. O caminho do conhecimento é perguntar dentro da cotidianidade e encontrar a resposta na cotidianidade do aluno e na sua cultura: mais que ensinar e aprender um conhecimento é preciso concretizá-lo no cotidiano (SAVIANI, 2000, p. 41).

Hoje o trabalho e a história dessas mulheres desperta a curiosidade em segmentos da instituição e instiga o desenvolvimento de outros trabalhos e reflexões acerca de uma educação que faça sentido na vida das pessoas e que seja contextualizada ao clima, a vegetação da região, aos saberes e valores construídos pelos educandos e educandas. É nesse sentido que esse artigo se justifica na necessidade de discutirmos sobre a importância do vínculo da instituição escolar e a sua função na sociedade atual. Uma educação que tenha início nas experiências e vivências locais, mas que também possa fazer conexões com outros saberes. E, assim, como sugere Freire (1996), estimular, "a capacidade de aprender não apenas para nos adaptar mas sobretudo para transformar a realidade, para nela intervir, recriando-a”. (FREIRE, 1996, p. 68-69). Nesse sentido, o ensino precisa estar voltado para a apreensão da realidade. 


\section{2- REFERENCIAL TEÓRICO}

\section{1- Contexto e intervenções}

A realidade é um todo dialético e estruturado, produzido por um conjunto de fatos que se inter-relacionam e que podem ser compreendidos, mas não predeterminados ou previstos (CIAVATTA; FRIGOTTO; RAMOS, 2005). Dessa forma, o educando deve ser orientado para que possa intervir nesse mundo que o cerca, sendo principalmente o agente da sua própria história. Assim como o estudante da zona urbana, o discente da zona rural também pode ser o ator e autor da sua história agregando e ampliando seus conhecimentos sobre a vida, a ciência, a cultura, o meio ambiente e o mundo que o cerca.

A intervenção do discente em sua realidade pode acontecer de maneiras diversificadas. A partir do conhecimento e do diálogo permanente, educador e educando podem provocar, por exemplo, a mudança de comportamento frente ao desgaste dos recursos naturais, os quais, no meio rural, decorrem em boa parte das práticas convencionais errôneas.

A mudança de comportamento do humano e dos fenômenos naturais presentes no meio rural, vem exigindo cada vez mais que os produtores e produtoras adotem medidas de racionalização no uso dos recursos naturais. Busca-se assegurar que, concomitante à luta pela sobrevivência das atuais e futuras gerações, haja preocupação e ação de preservação da natureza dentro de um contexto com base ecológica em silvicultura, pecuária e agricultura, por exemplo.

Parte desta mudança pode-se ver na relação cada vez mais próxima e direta do produtor com o consumidor por meio da comercialização dos produtos excedentes e que vem se caracterizando uma nova forma de relação para além do mercantil, mas que se leva em consideração não só a preocupação e o respeito pela e com a terra, há também expressão da solidariedade como valor humano, sentimento de cuidado com o outro através da disponibilização de uma gama de produtos alimentares saudáveis e que levam a uma melhor qualidade de vida de quem os consome.

\footnotetext{
A agricultura ecológica permite aproveitar melhor a mão-de-obra familiar, diminui os custos de produção, aumenta as possibilidades de comercialização direta considera básica a saúde dos consumidores, agrega novos valores de solidariedade e traz consideráveis benefícios para a sociedade e a natureza. (RUSCHEINSKY; DE VARGAS, 2002, p.140 et al ).
}

Ao lembrar a importância da agroecologia nessas discussões, convém discorrer e retomar um pouco o pensamento de autores como a pioneira em agroecologia no Brasil, Ana Primavesi que critica o atual modelo convencional da agricultura e defende que a 
agroecologia não é uma alternativa excêntrica de cultivo do solo, e sim a única possibilidade, se o ser humano pretende sobreviver no Planeta Terra. Para a autora,

[...]a agricultura ecológica somente pode usar o enfoque holístico, geral. E como na agricultura convencional tudo foi com receitas, os agricultores esperam também por receitas e não compreendem, que somente pode funcionar por conceitos, simplesmente porque cada lugar tem seu eco-sistema todo particular". (PRIMAVESI, 2009, p. 9).

Primavesi (2009) chama a atenção, nesse sentido, para a importância do respeito às peculiaridades locais na produção ecológica. O primeiro passo para isso, é o conhecimento do meio rural como fonte de sobrevivência, e de engrandecimento de uma comunidade. Esse conhecimento faz-se necessário antes de qualquer coisa.

A questão vai além de sobrevivência, pois a terra para os camponeses é lugar de segurança, de trabalho, de geração de renda e de tranquilidade, e as vivências com o meio ambiente transformam-se em escola com lições para toda a vida.

Nesse sentido, mesmo com alguns avanços destacados na área agrícola aqui no Brasil, ainda é preciso tratar o tema sobre agricultura familiar com mais rigor, em busca de maiores entrosamentos entre as políticas públicas, a escola e às comunidades da zona rural, uma vez que é do nosso conhecimento o descaso para com essa população. Para Guanziroli (2001, p.15) "o apoio à agricultura familiar é uma realidade em países com melhores índices de desenvolvimento, como os Estados Unidos e Japão. Tais países apresentam traços em comum no que se trata do acesso a terra, e ainda do incentivo à reforma agrária." Com isso compreende-se que, mesmo em países de muita evolução tecnológica e científica, a agricultura familiar é apoiada e incentivada.

Discorrer sobre as experiências agroecológicas vivenciadas pelas estudantes egressas do Campus Crato, especificamente do curso Técnico Subsequente em Agropecuária, propõe uma reflexão sobre as vivências adquiridas e aprimoradas por essas comunidades rurais que buscam a amplitude do seu cabedal de conhecimentos nos remetendo a Paulo Freire quando o teórico e educador destaca a importância de refletir não apenas de maneira intelectual, mas principalmente uma reflexão que conduza à prática.

Ao defendermos um permanente esforço de reflexão dos oprimidos sobre suas condições concretas, não estamos pretendendo um jogo divertido em nível puramente intelectual. Estamos convencidos, pelo contrário, de que a reflexão, se realmente reflexão, conduz à prática. (FREIRE, 2016, p.29)

A experiência adquirida no campo, dialogada com a técnica e o conhecimento construído e apreendido na instituição escolar apontam para uma formação do ser humano de maneira global e significativa. 
Dessa forma, compreende-se essa aquisição como uma construção coletiva, de forma dialética em que "Educador e educandos (liderança e massas), co-intencionados à realidade, se encontram numa tarefa em que ambos são sujeitos no ato, não só de desvelá-la e, assim, criticamente conhecê-la, mas também no de re-criar este conhecimento." (FREIRE, 2016, p.31)

Ao trazer os seus saberes para a sala de aula, alicerçados na experiência e na transmissão de geração em geração e transformados a partir da orientação, direcionamento, e consequentemente a troca de aprendizagem com o professor, esses alunos estão contribuindo para a transformação da realidade em que vivem e para com a formação do seu professor. Para Freire:

Desta maneira, o educador já não é o que apenas educa, mas o que, enquanto educa, é educado, em diálogo com o educando que, ao ser educado, também educa. Ambos, assim, se tornam sujeitos do processo em que crescem juntos e em que os "argumentos de autoridade" já, não valem. Em que, para ser-se, funcionalmente, autoridade, se necessita de estar sendo com as liberdades e não contra elas (FREIRE, 2016, p.39).

A educação que se preocupa com a transformação do educando e se propõe a ser um instrumento a mais na vida dos seus alunos é, como diz Freire (2016, p. 31) uma “[...] educação como prática da liberdade, ao contrário naquela que é prática da dominação, implica na negação do homem abstrato, isolado, solto, desligado do mundo, assim também na negação do mundo como uma realidade ausente dos homens."

\section{2 - Algumas reflexões sobre Educação contextualizada}

A aprendizagem construída pelo ser humano norteará o seu percurso de vida e poderá auxiliar no desenvolvimento de um pensamento crítico e reflexivo nas diversas situações do cotidiano. Existe, nesse sentido, a necessidade de homens e mulheres relacionarem o conhecimento científico com o contexto social em que vivem, para assim dar significado ao aprendizado.

Nesse âmbito, Freire (2011) lembra que ensinar é uma prática social, além de ser uma ação cultural. Com isto, concretiza-se na interação entre educadores e educandos, refletindo a cultura e os contextos sociais a que pertence. E essa reflexão também está presente em outros textos e documentos norteadores do processo educativo.

Os Parâmetros Curriculares Nacionais de 1996, por exemplo, trata a Contextualização como base metodológica que muito favorece a aprendizagem dos educandos considerando "essencial para compreensão e intervenção na realidade numa perspectiva de autonomia". 
Nessa perspectiva o processo de ensino e aprendizagem deve ser concretizado levando em conta o contexto social, os conhecimentos prévios, as experiências e peculiaridades do discente, onde os conhecimentos adquiridos tenham significado para a vida do educando.

A educação contextualizada é uma atividade humana que garante o exercício do papel social da humanidade na sociedade e a forma pela qual se inicia o processo de compreensão do mundo físico, possibilitando ao discente interagir, criar, modificar e assimilar o conhecimento da realidade.

Um ensino de qualidade que busca formar cidadãos capazes de interferir criticamente na realidade para transformá-la deve também contemplar o desenvolvimento de capacidades que possibilitem adaptações às complexas condições e alternativas de trabalho que temos hoje e a lidar com a rapidez na produção e na circulação de novos conhecimentos e informações, que tem sido avassaladores e crescentes. A formação escolar deve possibilitar aos alunos condições para desenvolver competências e consciência profissional, mas não se restringir ao ensino de habilidades imediatamente demandadas pelo mercado de trabalho. (BRASIL, 1996, p.34)

Ricardo (2003) também menciona os pontos positivos de uma educação que faz sentido na vida das pessoas. Segundo o autor "a contextualização visa dar significado ao que se pretende ensinar para o aluno [...], auxilia na problematização dos saberes a ensinar, fazendo com que o aluno sinta a necessidade de adquirir um conhecimento que ainda não tem". (RICARDO, 2003, p. 11).

Enquanto instituição que tem como finalidade a organização social em que os seres humanos constroem conhecimento e onde ocorrem múltiplas relações sociais, a escola é também um espaço onde a relação teoria e prática deve ser consolidada, apresentando-se como fundamental no desenvolvimento humano.

Os investimentos em Educação como direito e garantia de expansão dos conhecimentos e informações através das instituições que as detêm, que por sua vez têm papel decisivo na Educação para o trabalho, para a cidadania, e na percepção do meio ambiente e seus diversos recursos; favorecerá a adoção de medidas que instiguem a convivência harmoniosa com a natureza. Sem, nesse âmbito, degradá-la, sem destruí-la, mas com práticas e manejos agroecológicos, respeitosos e adequados às necessidades, especialmente diante dos fenômenos vivenciados no semiárido brasileiro, que requer ações que promovam agregação de valores às práticas ambientais cotidianas.

Políticas de fortalecimento da educação especialmente ambiental como processo e instrumento de capacitação humana e também para o trabalho, constituem-se na contemporaneidade imprescindíveis para a transformação da sociedade.

É dever da escola, desse modo, promover momentos diversos de aprendizagem com 
recursos e ambientes adequados, onde os discentes adquiram novos conhecimentos e aprimorem os que já possuem. A escola deve ser norteadora do conhecimento, estimulando a imaginação e a investigação em que teoria e prática possibilitem a construção de hipóteses que conduzem o homem a produzir, refletir e modificar a realidade em que vive. E a partir de então, promover o desenvolvimento do pensamento, da linguagem e da socialização.

Uma educação contextualizada requer uma prática educacional em que os conhecimentos científicos sejam os mais próximos do contexto social do discente, fazendo com que o mesmo perceba de forma significativa a relação dos conteúdos com o seu dia-adia.

Quando o conhecimento faz sentido na vida do discente, é nítido o interesse do mesmo, tendo em vista que não faz sentido o conhecimento de algo que não seja possível a percepção de sua utilidade. É necessário um conhecimento significativo onde instigue o educando a querer aprender mais e mais e a exercer seu papel de cidadão transformador em busca de um mundo melhor.

Os currículos escolares, nesse contexto, devem respeitar a realidade regional. Isso permitirá a inserção de docentes e discentes nas discussões e práticas inerentes a comunidade, gerando problematizações que pode trazer intervenções relevantes.

\section{3- Breve discussão sobre Convivência com o Semiárido Brasileiro (SAB)}

Nesse cenário de narrativas e reflexões a educação formal tem papel relevante. Ao se abrir para as discussões sobre convivência com o meio ambiente/ convivência com o Semiárido $\left(\mathrm{SAB}^{9}\right)$, a escola pode promover o “estalo" necessário ao conhecimento da realidade. E assim, passar a estimular a busca por informações relevantes ao contexto ambiental e climático, a provocar os seres humanos a abrirem os olhos para as questões responsáveis pela constituição social e política da região semiárida do Brasil, por exemplo, e assim passar a não mais assumir uma postura ingênua diante da realidade regional.

É preciso atentar-se para os conceitos acerca da região semiárida e ao processo histórico, político e social da sua formação. É necessário, inicialmente, compreender que o Semiárido Brasileiro é um território diverso. A sua extensão territorial desde o início do século XX vem sendo discutida. Inicialmente o fator preponderante das delimitações foram os critérios pluviométricos. Contudo, conforme os documentos do Ministério da Integração

\footnotetext{
${ }^{9}$ Sigla utilizada para abreviar a expressão Semiárido Brasileiro.
} 
Nacional (Brasil, 2008), a partir de estudos sobre climatologia, é definida uma nova delimitação regional baseada em três critérios: o da precipitação pluviométrica (média anual inferior a $800 \mathrm{~mm}$ ), o índice de aridez (de até 0,5 ), e o risco de seca (maior que $60 \%$ ).

O semiárido Brasileiro corresponde a região que hoje representa mais de $11 \%$ do território brasileiro com uma população de quase 23 milhões de pessoas (IRPAA, 2015) distribuídas em 1.262 municípios. (SUDENE, 2017) ${ }^{10}$. Vale a pena, com isto, conhecer melhor os cenários e as narrativas históricas para compreender a organização atual do ambiente semiárido e, assim, descobrir porque a carência e o atraso ainda persistem embora existam iniciativas e alternativas apropriadas a esse espaço.

Entre as características climáticas citadas, observa-se também que na região há oscilações quanto as precipitações de chuva. Assim, enquanto em um ano pode chover $300 \mathrm{~mm}$ em outro podemos ter uma precipitação de $800 \mathrm{~mm}$ de chuva. Isto, contudo, não pode representar um obstáculo para a vida no $\mathrm{SAB}$.

E nesse processo, também é essencial considerar as técnicas mais adequadas para melhor harmonia do ser humano com o meio ambiente. Para uma produção agropecuária adequada é preciso desenvolver tecnologias que foram negadas aos povos do semiárido desde o período da colonização do país. Para tanto, é preciso conhecer bem como o clima se comporta. Assim, tornar-se-á mais fácil manter o equilíbrio entre as ações do ser humano com o meio ambiente.

\begin{abstract}
No semiárido brasileiro, perdemos esse momento histórico de desenvolvimento de tecnologias localmente apropriadas. A população, depois da colonização, foi violentamente proibida de dar continuidade ao modo de vida dos nativos e de produzir novas tecnologias. A não posse da terra e da água foi a principal estratégia usada pelos colonizadores para coibir esse desenvolvimento. [...] As famílias que não tem posse da terra, estão sempre na posição de agregados ou arrendatários. Nessa situação, a pessoa não pode fazer grandes investimentos na terra. (SANTOS, 2010, p. 85).
\end{abstract}

O autor reforça suas menções inerentes ao processo histórico quando aponta algumas saídas para essa realidade já arraigada. Segundo Santos (2010) “[...] nos resta agora reconhecer esse grande prejuízo e minimizar seus efeitos. Para isso precisamos do tripé terra, água e conhecimento - para produzir novas técnicas e tecnologias de convivência com o semiárido. (Ibid, p. 86).

A partir do direito garantido a terra, água e educação, a região aqui citada, poderá ter

\footnotetext{
${ }^{10}$ Dados obtidos a partir da consulta à Resolução N ${ }^{\circ} 115$, de 23 de novembro de 2017 do Conselho Deliberativo da Superintendência de Desenvolvimento do Nordeste (SUDENE); que acrescenta municípios à região Semiárida. Assim, o território pertencente ao novo semiárido brasileiro é formado por municípios presentes nos estados de Maranhão, Alagoas, Bahia, Ceará, Paraíba, Pernambuco, Piauí, Rio Grande do Norte, Sergipe e Minas Gerais.
} 
suas características ainda mais potencializadas, com prosperidade e sustentabilidade. E como uma das características do SAB é a irregularidade da chuva no tempo e no espaço, é essencial considerar essa peculiaridade no planejamento da produção agropecuária. Convém, nesse sentido, mencionar algumas das iniciativas e tecnologias que precisam ser consideradas no planejamento e assim implementadas. Entre as técnicas mais comuns estão as seguintes: cisterna de consumo humano, filtro caseiro, barreiro de salvação ${ }^{11}$, barragem subterrânea, cisterna de produção (também conhecida como cisterna calçadão), bomba d'água popular (BAP), barreiro Trincheira ou caxio ${ }^{12}$, captação de água de chuva in situ ${ }^{13}$, domesticação de plantas nativas, recaatingamento ${ }^{14}$, fenação, melhoramento genético do rebanho e tantas outras que conseguem aliar o equilíbrio ambiental com a produção agropecuária.

São tecnologias milenares, mas que para muitos camponeses e camponesas ainda são desconhecidas. Assim, um dos maiores desafios é ampliar o acesso e o conhecimento a essas e outras técnicas até torná-las de senso comum. Um meio para isso é o conhecimento aliado ao acesso a terra, a água e a educação.

\section{3- METODOLOGIA}

Para alcance dos objetivos pretendidos neste estudo, revisitamos pesquisas que apresentam a temática da agroecologia, meio ambiente e educação e convivência com o meio ambiente, especialmente o meio semiárido como o foco e que puderam subsidiar esse trabalho. A presente investigação aponta interesse em "gerar conhecimentos novos úteis para o avanço da ciência sem aplicação prática prevista. Envolve verdades e interesses universais." (GIL, 1999).

A forma de abordagem é qualitativa, porque, segundo Maria Cecília de Souza Minayo (1992, p.21) essa abordagem “[...] responde a questões muito particulares. Ela se preocupa nas ciências sociais com um nível de realidade que não pode ser quantificado." Contudo, compreendemos a necessidade de dados e informações para análise da realidade a ser pesquisada. Desta forma, temos como compreensão que os dados qualitativos e quantitativos não são opostos, “[...] se complementam, pois a realidade abrangida por eles interage dinamicamente, excluindo qualquer dicotomia." (Ibid, p. 22).

\footnotetext{
11 Tanque produzido com terra que armazena água suficiente para realizar uma ou duas irrigações de uma determinada área de plantio. Tem como objetivo suprir a carência de água no mês em que não choveu.

12 Tanque comprido, estreito e profundo, escavado em solo rochoso. Por ter esse formato, o barreiro diminui a lamina de água exposta ao sol e ao vento, diminuindo a evaporação.

${ }^{13}$ In situ quer dizer "No lugar". Assim, é preciso captar o máximo de água possível, no local onde a planta se encontra.

${ }^{14}$ Termo usado para designar o cuidado e o repovoamento da caatinga com plantas arbóreas que são quase inexistentes.
} 
O método científico utilizado nesse estudo é a abordagem dialética que, segundo Minayo:

[...] se propõe a abarcar o sistema de relações que constrói, o modo de conhecimento exterior ao sujeito, mas também as representações sociais que traduzem o mundo dos significados. A Dialética pensa a relação da quantidade como uma das qualidades dos fatos e fenômenos (MINAYO, 1998, p. 24).

A pesquisa de campo fez-se necessária nesse trabalho para subsidiar esse estudo. Segundo Minayo (1998) “[...] o campo torna-se um palco de manifestações de intersubjetividades e interações entre pesquisador e grupos estudados, propiciando a criação de novos conhecimentos" (1998, p. 54). Para colher as informações apresentadas pelo público alvo pesquisado, que foi a agricultora Damiana, utilizou-se de uma técnica de coleta de dados, sendo aqui explorada a entrevista semiestruturada que articula características da entrevista estruturada e não estruturada, possibilitando um leque maior de conhecimento da realidade do entrevistado.

Além da observação constante à rotina que culminou nesse trabalho, questionários foram utilizados para a coleta dos dados. O objetivo foi agir de maneira mais leve e natural possível durante as entrevistas as quais estiveram guiadas por questionamentos diversos. Assim, a entrevista semiestruturada, com perguntas abertas teve como objetivo responder a questionamentos sobre as experiências agroecológicas adquiridas pela família da estudante egressa e produtora rural Damiana na sua comunidade e na escola. E com isto fosse possível comparar a realidade investigada com os resultados apresentados no referencial teórico, a fim de obtermos os resultados esperados nos objetivos deste estudo.

Para alcançar os objetivos fez-se um percurso metodológico de cunho qualitativo promovendo um diálogo entre os autores, instrumentalizado em entrevista com a ex-discente supracitada fundamentado em um estudo teórico e bibliográfico nos teóricos: FREIRE (1996; 2016); SAVIANI (2000); CERVO; BERVIAN; DA SILVA (2007); GUANZIROLI (2001) e SANTOS (2010) que tratam do tema com sua devida importância.

A maior intenção é descrever experiências que culminem na reflexão e discussão sobre a importância das experiências agroecológicas de discentes e pesquisadoras como integrantes dos trabalhos da instituição. Tudo isto caracteriza a pesquisa como descritiva, por registrar, analisar e correlacionar fatos. (CERVO; BERVIAN; DA SILVA, 2007).

\section{4-RESULTADOS/DISCUSSÕES}

\section{1- Caminhos e Proposições}


O público presente no auditório do IFCE Campus Crato, de repente volta a atenção para uma pessoa que está na plateia. Palavras firmes e diretas vêm de uma mulher que fala sobre a sua experiência de vida. Seu jeito eloquente e seguro logo responde a um dos questionamentos de outro discente o qual demonstra duvidar do retorno financeiro da produção agrícola natural, livre de produtos químicos. A pergunta do discente é direcionada a um dos palestrantes. Mas, sem demora, Damiana Vicente da Silva (que na época era estudante), tem acesso ao microfone e menciona um pouco a sua experiência. Logo, todos ficam admirados e contemplados com a resposta e reação da estudante que afirma com veemência que a agricultura familiar, orgânica e sustentável além de ser um bem precioso à saúde e ao meio ambiente, também é rentável financeiramente, pois o que a sua família é hoje e o que possui vem dessa produção. "Todos lá em casa vivem da agricultura familiar e orgânica. Não faltam pessoas querendo adquirir os produtos. A procura é muito grande. Hoje eu sou testemunha do que é real". Revelou Damiana em parte do seu relato, inesperado, durante a décima edição da Semana do Meio Ambiente (SEMEIA 2016) do IFCE - Campus Crato.

A afirmação da estudante mencionada foi só um pequeno trecho do que ela relatou e do que vem demonstrando no IFCE com relação às possibilidades de construção de uma agricultura e agropecuária saudável em todos os sentidos e que favorece a biodiversidade. São confirmações de quem acredita, experimenta e vivencia a produção agrícola sustentável. Um trabalho que teve início a partir da observação, quando Damiana e seu esposo Valdemiro dos Santos (44), perceberam que não dava mais certo o monocultivo da mandioca devido ao longo tempo dispensado em uma só cultura e que gerava a degradação do meio ambiente. Com a atenção voltada apenas para um tipo de cultivo, a família deixava, por exemplo, de conservar a vegetação que fazia as abelhas produzirem mel.

A partir de então, as práticas e concepções mudaram. Aliada a mudança de comportamento, começaram as assessorias prestadas pela Organização ACB mediante formações de agentes multiplicadores e elaboração de projetos de produção e sistemas integrados. Com isto, a família começou a usar pouca água no cultivo e manejo agropecuário, a voltar a atenção para a produção melífera (hoje o mel é a maior fonte de renda desses produtores), a criar animais de pequeno porte (adaptados a realidade climática da região), a desenvolver sistemas agrícolas adequados a agricultura e pecuária local (exemplo da mandala), a agir com respeito a natureza e conservação dos recursos naturais; enfim aprenderam a abraçar uma causa e vivenciá-la cotidianamente.

Os aprendizados construídos com as formações, assessorias, observações e vivências 
foram essenciais para a mudança de hábitos, que na visão da família, são ainda melhor trabalhados a partir do acesso a mais informações e conhecimentos construídos na instituição de ensino.

\section{2- Educação para a vida}

"Hoje já podemos passar informações para outros agricultores com mais segurança. Mesmo encontrando na escola algumas ideias contrárias às nossas, valem a pena os conhecimentos construídos". Ressaltou Damiana ao falar sobre a importância da educação formal para o seu processo cotidiano com a roça. Assim, com frequência a estudante lembra que o seu maior objetivo em cursar agropecuária foi a possibilidade de ampliar o conhecimento com o aprendizado de novas técnicas de produção e assim melhorar a sua prática.

A relação entre teoria e prática é evidente quando os professores e professoras levam toda a turma para realizar atividades na propriedade de Damiana e sua família. Conteúdos ligados a olericultura, apicultura, culturas anuais, cooperativismo, suinocultura caprinovinocultura e outras áreas já foram trabalhados durante as visitas técnicas no ambiente rural mencionado, tudo numa perspectiva agroecológica. Além disso, algumas palestras, oficinas e outros eventos são ministrados na instituição com a ajuda da estudante e suas experiências de vida que são complementadas com o conhecimento científico. Atualmente Damiana também é uma das integrantes do Núcleo de Educação Contextualizada (NEC) do campus. Isto fortalece a crença de que "A educação pautada nos princípios da convivência com o meio ambiente (natural e social) permite a formação holística de homens e mulheres, fortalecendo a sua identidade e criando novas possibilidades no relacionamento destes com o mundo". (IRPAA 2003, p.13).

Nesse contexto de aprendizados, quando os professores e professoras solicitam aos estudantes alguns trabalhos, ao conhecerem a história de vida de Damiana, os discentes preferem fazê-los com foco na produção rural sustentável. Exemplo disto são as pesquisas realizadas e alguns projetos elaborados com temas agroecológicos, dentre eles "Produção de alface orgânica", "Produção de tomate orgânico" e outros. O desejo de muitos estudantes é que o IFCE, campus Crato possa ampliar ainda mais os projetos de extensão voltados para as comunidades rurais. E assim voltar a atenção aos produtores e a produtoras rurais da região. Nesse sentido, Damiana, enquanto Técnica em Agropecuária recém-formada, lembra que a maioria dos seus colegas de turma eram filhos e filhas de agricultores (as) familiares e por 
isso os estudos da instituição precisam estar ainda mais voltados à realidade para que os discentes de hoje sejam os pesquisadores (as) e agricultores (as) experimentadores (as) de amanhã e tenham autonomia para agir de maneira sustentável.

No tocante ao respeito aos saberes como também ao questionamento acerca dos conteúdos trabalhados há uma proposição de Freire (1996) pertinente, quando ele lembra que

[...] pensar certo coloca ao professor, ou, mais amplamente a escola, o dever de não só respeitar os saberes com que os educandos, sobretudo os das classes populares, chegam a ela - saberes socialmente construídos na prática comunitária - mas também, como há mais de trinta anos venho sugerindo, discutir com os alunos a razão de ser de alguns desses saberes em relação com o ensino dos conteúdos. (FREIRE, 1996, p.30).

O autor e educador Paulo Freire complementa a sua reflexão quando enfatiza que "[...] o pensar certo que supera o ingênuo tem que ser produzido pelo próprio aprendiz em comunhão com o professor formador". (FREIRE, 1996, p. 39). Isto reforça a compreensão que as experiências dos educandos e educandas do IFCE Campus Crato precisam ser valorizadas e complementadas com o apoio dos educadores e educadoras.

\section{CONSIDERAÇÕES FINAIS}

Diante do que foi exposto, convém reafirmar a urgência de as intuições de ensino debruçarem-se sobre a educação contextualizada ao meio ambiente (natural e social). E assim incorporarem muito mais vida e perspectivas em seus conteúdos, estudos e práticas. É preciso estar atento ao que pulsa e acontece por entre as rodas de conversa, troca de experiências, dizeres e fazeres dos discentes, que em alguns momentos são silenciados pelas propostas universalistas. É preciso provocar e manter um diálogo permanente entre a instituição de ensino e a comunidade.

O que às vezes é considerado currículo oculto pode ganhar sentido nas pesquisas, experimentos e cotidiano, a exemplo do que ocorre com Damiana e sua família.

A produção rural sustentável precisa, nesse âmbito, ser priorizada e fazer parte do currículo oficial, não mais encarada como uma proposta à parte, alternativa ou complemento que fica à margem das ideias já padronizadas e sacralizadas pelo currículo. Assim, ficará mais viável internalizar e vivenciar a agroecologia.

\section{REFERÊNCIAS BIBLIOGRÁFICAS}

BRASIL. MIN. Ministério da Integração Nacional/Secretaria de Políticas de Desenvolvimento Regional. Nova delimitação do Semiárido Brasileiro. Brasília (DF), 2008. 
BRASIL, Parâmetros Curriculares Nacionais - Apresentação - Versão agosto / 1996.

Brasil. Resolução $\mathbf{n}^{\circ} \mathbf{. 1 1 5} / \mathbf{2 0 1 7}$. Superintendência do Desenvolvimento do Nordeste. SUDENE. Acrescenta municípios a relação aprovada pela Resolução CONDEL nº 107, e 27 de julho de 2017.

CERVO, Amado Luiz; BERVIAN, Pedro Alcino; DA SILVA, Roberto. Metodologia

Científica. São Paulo: Pearson Prentice Hall, 2007.

FREIRE, Paulo. Educação como prática da liberdade. Rio de Janeiro: Paz eTerra, 2011.

FREIRE, Paulo. Pedagogia da autonomia: Saberes necessários à prática educativa. São Paulo: Paz e Terra, 1996.

FREIRE, P. Pedagogia do Orpimido. Disponível em: https://vivelatinoamerica.files.wordpress.com/2014/03/pedagogia do oprimido paulo freire. pdf. Acesso feito em: 12 de julho de 2016.

GIL, A.C. Métodos e técnicas de pesquisa social. 4 ed. São Paulo: Atlas, 1999. 207 p.

GUANZIROLI, Carlos E. et al. Agricultura Familiar e Reforma Agrária no século XXI. Rio de Janeiro: Garamond, 2001. 288p.

IRPAA. Referencial Curricular de Educação para convivência com o Semiárido. Bahia: Juazeiro: (mimeo), 2003.

IRPAA, Instituto Regional da Pequena Agropecuária Apropriada. 25 anos trabalhando pela Convivência com o Semiárido. Juazeiro-BA, 2015.Revista em comemoração aos 25 anos da instituição.

KAGEYAMA, A. Desenvolvimento rural: conceito e medida. Brasília: Cadernos de Ciência \& Tecnologia, v. 21, n. 3, p. 379-408, set./dez. 2004. Disponível: http://webnotes.sct.embrapa.br/pdf/cct/v21/v21n3p379.pdf. Acesso dia 30 de outubro de 2011.

Lei № 9394, de 20 de dezembro de 1996. Lei de Diretrizes e Bases da Educação Nacional. Estabelece as diretrizes e bases da educação nacional. Brasília,1997.

LIMA, Elmo de Souza. O Currículo como espaço de diálogo entre as diversidades socioculturais do Semiárido in: Rede de Educação do Semiárido - RESAB .Semiárido Piauiense: Educação e Contexto (Orgs) Conceição de Maria de Sousa e Silva: Elmo de Souza Lima; Maria Luiza de Cantalice; Maria Tereza de Alencar; Wladirene Alves Lopes da Silva. INSA. Campina Grande: 2010. p.160- 236.

MINAYO, M. C. S. O desafio do conhecimento: pesquisa qualitativa em saúde. São Paulo: Hucitec/ABRASCO, 1992.

MINAYO, M. C. S. Pesquisa Social: teoria, método e criatividade. 9. ed. Petrópolis: Vozes, 1998.

PRIMAVESI, Ana. Cartilha do Solo: Como reconhecer e sanar seus problemas. São Paulo: 
MST, 2009.

RICARDO, E.C. Implementação dos PCN em sala de aula: dificuldades e possibilidades.Caderno Brasileiro de Ensino de Física. Florianópolis, v. 4, n. 1, 2003.

RUCHEINSKY, Aloísio; DE VARGAS, Sérgio Hiandui Nunes. Agroecologia e Reforma Agrária: integração possível e necessária. In: RUCHEINSKY, Aloísio et al. Educação Ambiental: abordagens múltiplas. Porto Alegre: Artmed, 2002.

SANTOS, José Moacir dos. Tecnologias para o Semiárido. In: INSA: Instituto Nacional do Semiárido. Semiárido Piauiense: Educação e Contexto. Campina Grande, INSA, 2010. p. 83-105.

SAVIANI. D. Saber escolar, currículo e didática. Campinas: Autores Associados, 2000. 